\title{
Principais Rotas de Síntese de Resinas Complexantes de Mercúrio
}

\author{
Luciana da Cunha, Ailton S. Gomes \\ Instituto de Macromoléculas, UFRJ \\ Fernanda M. B. Coutinho \\ Instituto de Química, UERJ, \\ Instituto de Macromoléculas, UFRJ

\section{Viviane G. Teixeira \\ Departamento de Química, UFRRJ}

\begin{abstract}
Resumo: A recuperação de espécies contendo mercúrio utilizando resinas complexantes obtidas a partir da modificação de suportes poliméricos vem atraindo cada vez mais a atenção dos pesquisadores. São muitas as combinações de suportes e grupos complexantes para a síntese desses materiais. Assim, este trabalho apresenta uma revisão sobre os principais grupos funcionais avaliados, bem como as rotas de síntese adotadas para a imobilização desses grupos nos suportes. É abordada também a problemática da síntese de uma resina eficiente, produzida a partir de um processo limpo e acessível às indústrias que utilizam mercúrio em seus processos.
\end{abstract}

Palavras-chave: Resinas complexantes, mercúrio, copolímeros de estireno e divinilbenzeno, rotas de síntese.

\section{Chelating Resins for Recovery of Mercury: The Main Routes of Synthesis}

Abstract: The recovery of mercury and its compounds by using chelating resins produced by modification of polymer supports has been studied by many researchers. There are many combinations of supports and functional groups for producing chelating resins that are appropriate for mercury complexation. This paper presents an overview of the main functional groups applied for mercury complexation and the routes used for immobilization of these groups in polymer supports. Also discussed are the problems involved in the synthesis of an efficient chelating resin, produced through a non-polluting route, which are appropriate for companies employing mercury in their processes.

Keywords: Chelating resins, mercury, styrene-divinylbenzene copolymers, synthesis routes.

\section{Introdução}

Os primeiros registros de utilização do mercúrio e do minério cinabre $(\mathrm{HgS})$ datam de mais de 2300 anos, em cerimônias religiosas como ungüento medicinal e em processos de amalgamação. Por mais de mil anos os alquimistas utilizaram o mercúrio como a base para a transmutação e empregavam amálgamas para produzir imitações de ouro e prata. Já em 1643 o mercúrio foi introduzido em pesquisas científicas com a invenção do barômetro por Torricelli. Fahrenheit, em 1720, inventou o termômetro de mercúrio. Joseph Pristley foi o primeiro a utilizar esse metal como selante de gases solúveis em água em análise de gases. Em 1799, Howad preparou o mercúrio fulminante que passou a ser usado como detonador para explosivos e teve uma importante participação nas histórias de paz e guerras no mundo ${ }^{[1,2]}$.

Ao longo dos anos, as características do mercúrio, em suas formas químicas particulares, permitiram a sua utilização em diversos processos industriais. Até 1970 já eram co- nhecidos mais de seiscentos usos de mercúrio nas indústrias, tais como a produção de materiais elétricos e eletrônicos, que se deve à baixa resistência elétrica e alta condutividade térmica desse metal. A capacidade de formação de amálgamas com a maioria dos metais permite a sua aplicação em processos extrativos, na metalurgia e na odontologia. Já a sua elevada estereoespecificidade, quando da formação de compostos inorgânicos, possibilita o seu uso em catálise e na indústria de polímeros sintéticos ${ }^{[1-3]}$.

Além de sua extensa utilização, o mercúrio também é conhecido devido as suas particularidades no que diz respeito à intoxicação dos seres humanos. Dentre os metais tóxicos, ele vem sendo apontado como um dos poluentes mais perigosos. Isso se deve a sua propriedade única de, na forma metilada, apresentar um comportamento de bioacumulação.

O processo de bioacumulação de mercúrio é regulado pela concentração de mercúrio elementar, compostos inorgânicos e compostos orgânicos de mercúrio nos diferentes 
compartimentos ambientais e pela conversão dessas espécies em metilmercúrio e vice versa. As formas metilada e desmetilada do mercúrio permanecem em equilíbrio dinâmico nos diferentes ambientes, sendo que, em meio aquático, o equilíbrio encontra-se deslocado para os processos de metilação em função da propriedade de bioacumulação do metilmercúrio. O metilmercúrio se combina com as proteínas da biota aquática, atingindo altos valores de concentração nos tecidos dos peixes predadores, no topo da cadeia alimentar. Concentrações inócuas de mercúrio acabam por se transformar em concentrações tóxicas capazes de induzir alterações fisiológicas graves, quando do consumo desses peixes ${ }^{[3]}$.

A intoxicação dos seres humanos também pode ocorrer de forma direta por exposição aguda ou crônica aos compostos de mercúrio orgânicos e também aos sais inorgânicos. As formas metiladas são as mais rápidas e mais tóxicas de contaminação por mercúrio em função de sua lipofilicidade. Os sintomas decorrentes da exposição às formas organomercuriais são principalmente de origem neurológica. A exposição a baixos níveis pode comprometer as habilidades motoras, a linguagem, a audição e a visão. Em altas concentrações, podem causar retardamento metal, paralisia cerebral e até mesmo a morte. $\mathrm{O}$ metilmercúrio é particularmente prejudicial ao desenvolvimento de embriões e à saúde dos recémnascidos ${ }^{[4]}$.

O desastre mais grave que expôs ao mundo o risco da contaminação por mercúrio ocorreu em 1932 na Baía de Minamata (Japão), quando o consumo de pescado contaminado resultou na morte de milhares de pessoas. Também são difundidos os casos de contaminação ocorridos no Iraque, Paquistão, Gana e Guatemala, quando centenas de famílias morreram após consumir pão caseiro cujas sementes de trigo haviam sido tratadas com um fungicida à base de metil e etilmercúrio e a morte da pesquisadora Karen Wetterhahn vítima do contato direto com dimetilmercúrio. Acredita-se que algumas gotas de dimetilmercúrio tenham caído sobre a luva de látex da pesquisadora e penetrado em sua pele. $\mathrm{O}$ composto rapidamente atingiu o sistema nervoso central provocando alterações de ordem neurológica seguidas do coma que a levou à morte ${ }^{[3]}$.

No Brasil, uma pesquisa com índios Tapajós usando fios de cabelo como bioindicadores de contaminação por mercúrio revelou valores médios entre 10 e 15 partes por milhão (ppm). A OMS (Organização Mundial de Saúde) alerta que a concentração máxima permitida para mulheres grávidas é de 10 ppm. Contudo em muitos países essa concentração é de no máximo 6 ppm para essas mulheres. Trabalhos feitos no Estado de São Paulo também revelaram concentrações de mercúrio nos rios acima da permitida pela $\mathrm{OMS}^{[3-5]}$.

Além das fontes antropogênicas de contaminação associadas, principalmente, ao despejo de rejeitos por indústrias de cloro-soda, as atividades garimpeiras e as emissões devido à combustão de carvão e derivados de petróleo, processos naturais tais como emanações vulcânicas, o intemperismo, a ressuspensão de partículas do solo pelo vento e as queimadas das florestas também podem disponibilizar o mercúrio, que em uma outra etapa pode sofrer o processo de bioacumulação. Sob essa última forma de disposição de mercúrio, há uma preocupação muito grande com queimadas na floresta Amazônica. O solo daquela região contém grandes teores de mercúrio inorgânico. $\mathrm{O}$ desmatamento e as queimadas podem provocar a migração desse composto para os rios próximos e mesmo áreas distantes da floresta podem ser contaminadas. O mercúrio metálico fica retido por muito tempo na atmosfera e por isso pode ser transportado por grandes distâncias ${ }^{[5,6]}$.

Além de programas que substituam ou minimizem a utilização de mercúrio em processos industriais, é indispensável ainda tratar as águas já poluídas. Como a recuperação de íons metálicos, utilizando complexantes em fase líquida, é um processo pouco atrativo do ponto de vista ecológico e econômico, a imobilização de complexantes em matrizes poliméricas tem atraído cada vez mais atenção devido à simplicidade do processo de separação do íon e da necessidade de menor volume de agente de extração e de solvente nesse $\operatorname{processo}^{[7,8]}$.

Depois da síntese e da popularização da resina IDA, uma resina de estireno e divinilbenzeno (S-DVB) funcionalizada com ácido iminodiacético, e dos estudos de Merrifield sobre a síntese em fase sólida, diversos pesquisadores começaram a direcionar esforços no sentido de desenvolver resinas complexantes em substituição aos extratores líquido-líquido usados até então ${ }^{[9]}$.

O desenvolvimento de uma rota de síntese de baixo custo e que forneça resinas eficientes e seletivas para a remoção de mercúrio é de grande relevância para as indústrias que utilizam esse metal em seus processos. Além de se adequarem às exigências dos órgãos reguladores das questões ambientais é possível também pensar na possibilidade de reaproveitamento desse metal por essas indústrias.

A rota mais comum de produção de resinas quelantes consiste na inserção do complexante na matriz polimérica preparada previamente (suporte). As propriedades desses dois componentes, grupo quelante e suporte, irão determinar a eficiência e a aplicabilidade do material como um todo, para retenção de um íon ou uma classe de íons ${ }^{[8]}$.

\section{Características do Suporte}

Os suportes poliméricos mais utilizados na síntese de resinas adsorventes e de troca iônica são os copolímeros macroporosos, produzidos por polimerização de um monômero em presença de um agente de reticulação e de um agente formador de poros, também chamado diluente precipitante, ou agente porogênico. $\mathrm{O}$ monômero mais comumente usado é o estireno (S), seguido pelos acrilatos e as vinilpiridinas. $\mathrm{O}$ agente de reticulação usado em quase todas as reações de polimerização é o divinilbenzeno (DVB) ${ }^{[10]}$. A principal característica dos polímeros reticulados porosos que os distingue dos polímeros do tipo gel, seus antecessores, e os torna muito mais úteis como suportes para fins de catálise e de retenção 
de metais, é a presença de uma porosidade verdadeira ou permanente independente do ambiente no qual este suporte se encontre.

A maioria dos mecanismos de formação da estrutura porosa de copolímeros de S-DVB macrorreticulados tem em comum a existência de um processo de separação de fases entre o polímero e o sistema diluente durante a conversão das microgotículas monoméricas no estado líquido para micropérolas no estado sólido. Alguns parâmetros reacionais da síntese controlam a extensão da separação de fases, sendo responsáveis pela sua ocorrência em um estágio mais adiantado ou tardio da reação de polimerização, e conseqüentemente são determinantes na formação da estrutura porosa. Dentre esses parâmetros os mais estudados são a afinidade termodinâmica entre o sistema diluente e as cadeias poliméricas, a quantidade de diluente e o teor de monômero divinílico ${ }^{[1-22]}$.

O teor de DVB e o tipo e quantidade de diluente definem o grau de compactação dos núcleos, das microesferas e dos aglomerados de microesferas e como conseqüência o tamanho e a distribuição dos micro, meso e macroporos.

De uma forma geral, copolímeros S-DVB do tipo gel são formados na ausência de um diluente ou empregandose um diluente solvatante para as cadeias poliméricas. Esses materiais têm poros somente em presença de bons solventes e a quantidade e o tamanho dos poros é dependente, principalmente, do grau de reticulação das cadeias. Entretanto, quando o diluente é pouco solvatante em relação às cadeias poliméricas em formação, acontece o fenômeno de $\chi$-sinerese induzida e a separação de fases passa a ocorrer antes do ponto gel, resultando na dispersão da fase polimérica e na separação da fase líquida dentro dessa fase na forma de gotas. A incompatibilidade entre as moléculas do diluente e do polímero em formação é responsável pelo aparecimento da porosidade verdadeira, ou seja, pela presença dos poros fixos. O tamanho e a distribuição de poros nessa situação irá depender do balanço entre teor de DVB e razão diluente/fase monomérica. Baixos teores de DVB resultam na formação de materiais pouco porosos. Contudo, altas concentrações de monômero divinílico criam núcleos rígidos, e favorecem o aparecimento dos microporos e o aumento da área específica. Altos graus de diluição promovem o afastamento entre as cadeias de polímero em crescimento e a reticulação passa a ocorrer em uma estrutura mais expandida, se o teor de DVB for razoável, são formados suportes com poros de elevado diâmetro $^{[19]}$.

Freqüentemente, em vez de um solvente puro, usa-se uma mistura de solventes, com diferentes parâmetros de solubilidade, como diluente da mistura monomérica S-DVB, com o intuito de produzir copolímeros com tamanhos diferenciados de $\operatorname{poros}^{[13,17,22]}$. O processo de separação de fases e a formação da estrutura morfológica final, nesse caso, irão depender do teor de cada constituinte na mistura além da relação desse constituinte com as outras duas principais variáveis determinantes da porosidade, graus de reticulação e de diluição.
As características de porosidade do suporte influenciam drasticamente a extensão das reações de modificação e a localização dos grupos funcionais. Isso porque, a reação de funcionalização de uma matriz sólida é controlada por um processo de difusão ${ }^{[8]}$. A distribuição dos reagentes dentro e fora da matriz será diferente se essa matriz tiver maior porção gel ou se for porosa, no caso de uma matriz porosa se tiver maior quantidade de microporos ou poros de elevado diâmetro. Para materiais do tipo gel, altos graus de funcionalização podem ser alcançados somente na presença de bons solventes para as cadeias poliméricas. Contudo, como normalmente os processos de separação de íons metálicos acontecem em meio aquoso, apenas aqueles grupos complexantes localizados na superfície das resinas obtidas a partir de suportes do tipo gel estarão disponíveis para reagir. Já quando o suporte contém poros fixos, é possível a introdução de grupos funcionais e mais tarde a acessibilidade a estes grupos mesmo em meio aquoso.

Além da porosidade, o tamanho do suporte também é um fator crítico na separação de íons metálicos por resinas complexantes, principalmente quando estas são usadas em colunas cromatográficas. A polimerização em suspensão é o método mais empregado para a síntese de polímeros reticulados para aplicação como fase estacionária para processos de extração em fase sólida (SPE), uma vez que por essa técnica são normalmente obtidas partículas esféricas de tamanhos na faixa de 5 a $1000 \mu \mathrm{m}^{[7,23]}$.

Dentre os fatores reguladores do tamanho das partículas poliméricas e da sua polidispersão estão a razão entre as fases aquosa e orgânica, a velocidade e o formato da pá de agitação e o tipo e concentração do agente de suspensão. Os estabilizantes mais utilizados em suspensões óleo/água são gelatina, hidroxietilcelulose, e poli(álcool vinílico). Esse último polímero tende a fornecer pérolas menores. As partículas menores são preferidas para processos cromatográficos, uma vez que aumentam o número de pratos teóricos e conseqüentemente a eficiência do processo de separação.

Além dos copolímeros de S-DVB, os óxidos inorgânicos, particularmente sílica, são materiais amplamente usados como suportes para diversos complexantes de mercúrio e outros metais tóxicos ${ }^{[24-31]}$. Apesar do menor custo desses materiais, o tratamento de matrizes orgânicas é normalmente preferido em função da possibilidade de reciclagem e dos mais altos valores de capacidade normalmente obtidos. Além disso, os polímeros podem ser usados em toda faixa útil de $\mathrm{pH}$ e com todos os solventes, característica extremamente importante na etapa de funcionalização, no uso das resinas em diferentes ambientes e na escolha do eluente quando da dessorção do metal ${ }^{[7]}$.

\section{Características do Grupo Complexante}

A maioria das escolhas de grupos complexantes para íons metálicos leva em consideração a teoria de Pearson ${ }^{[32]}$. Pearson classificou os ácidos e bases de Lewis em ácidos e bases 
duros e moles. As principais características dos ácidos e bases moles são o elevado tamanho, a baixa relação carga/raio e a alta polarizabilidade, enquanto que os ácidos e as bases duras são pequenos e suas nuvens eletrônicas não sofrem distorções significativas. Os metais alcalinos e alcalino-terrosos são exemplos típicos de cátions duros, eles reagem com as bases duras via interações eletrostáticas. Os ácidos moles formam preferencialmente ligações covalentes com as bases moles. O caráter iônico da ligação ácido duro-base dura e o caráter covalente da ligação ácido mole-base mole são explicados em função da diferença (gap) de energia entre os orbitais envolvidos nessas ligações ${ }^{[33,34]}$.

Sendo o mercúrio inorgânico e as formas organomercuriais classificados como cátions moles, diversos compostos complexantes contendo átomos doadores de elétrons moles vêm sendo imobilizados em diferentes matrizes poliméricas com o objetivo de se obter uma resina complexante eficiente para a separação e/ou pré-concentração de mercúrio e/ou de seus derivados.

\section{Principais Rotas de Sintese Desenvolvidas para Produção de Resinas Quelantes}

A resina IDA foi a primeira resina comercial desenvolvida para a complexação de mercúrio e outros metais pesados. Diversas rotas de síntese para a produção dessa resina foram patenteadas e a mais difundida baseia-se na funcionalização de copolímeros S-DVB macroporosos com ácido iminodiacético. Dentre as resinas IDA disponíveis comercialmente destacam-se a Amberlite IRC 748 produzida pela Rohm and Haas Co. ${ }^{[35,36]}$, a Chelex 100 (Sigma Co. $)^{[37]}$, Lewatit TP-207 (Bayer) ${ }^{[3,37]}$ e Purolite S 930 (Purolite) $^{[36]}$.

Propostas para a introdução de grupos iminodiacético em resinas estirênicas, já contendo grupos polietilenoimina (PEI) ou grupos metilmercapto-hidroxietila, foram desenvolvidas por Saegusa $^{[38]}$ e por $\operatorname{Sun}^{[39]}$. Saegusa e colaboradores ${ }^{[38]}$ propuseram duas rotas para a carboxietilação de resinas estirênicas graftizadas com PEI (PS-PEI). O primeiro método envolvia a reação dessas resinas com ácido $\beta$-cloropropiônico neutralizado com uma base. A outra forma de carboxietilação era a reação da PS-PEI com ácido acrílico em meio de etanol (adição de Michael). Esta última rota era mais efetiva para a introdução dos grupos iminodiacético. No trabalho de Sun e colaboradores ${ }^{[39]}$, copolímeros S-DVB contendo grupos metilmercapto-hidroxietila eram reagidos com cloreto de benzenosulfonila, após inchamento em uma solução de tetracloreto de carbono, benzeno e piridina, e em uma etapa subseqüente, funcionalizados com ácido iminodiacético em meio de piridina. A resina de Saeguza, da mesma forma que as resinas IDA, retinha cálcio em elevados valores de $\mathrm{pH}$. Embora não tenham sido feitos testes, a resina de Sun provavelmente também retinha metais alcalino-terrosos.

Umas das propostas de Ahuja e colaboradores ${ }^{[40]}$ para a síntese de resinas com grupos hidroximato parte da modificação de resinas Chelex-100. De acordo com os autores, a introdução de grupos hidroximato nessas resinas aumentaria a seletividade para os metais tóxicos em detrimento dos metais alcalinos e alcalino-terrosos. Entretanto, o material produzido nesse trabalho ainda retinha teores consideráveis de cálcio.

A capacidade de reter metais alcalinos e alcalinos-terrosos é considerada uma desvantagem das resinas IDA. Esses íons metálicos estão presentes em grandes quantidades no meio aquático e podem saturar a resina antes que o metal pesado de interesse possa ser removido em uma extensão significativa. A retenção de íons metálicos por grupos iminodiacéticos pode ocorrer via formação de um complexo ou através de troca iônica, dependendo do $\mathrm{pH}$ do meio no qual essa resina se encontre ${ }^{[8,41,42]}$. A pequena diferença de energia livre envolvida nesse último mecanismo é responsável pela retenção de metais alcalinos e alcalino-terrosos. A capacidade de reter cátions duros também pode ser explicada considerando-se que a hidroxila é classificada como uma base dura.

Segundo Fritz e colaboradores ${ }^{[43]}$, elevados teores de grupos iminodiacetato contribuem para o aumento da capacidade das resinas IDA, entretanto favorecem também a ocorrência de troca iônica e dessa forma há um comprometimento da seletividade para os metais tóxicos. $\mathrm{O}$ aumento da seletividade pode ser conseguido com baixos teores de grupos iminodiacético. Contudo, a resina assim funcionalizada irá reter uma menor quantidade de íons metálicos.

A funcionalização de copolímeros de S-DVB com grupos ditiocarbamato fornece uma resina quelante capaz de remover um grande número de metais tóxicos, sem a interferência de metais alcalinos e alcalino-terrosos, como acontece com a resina $\mathrm{IDA}^{[44]}$. De uma forma geral, a introdução do grupo ditiocarbamato em copolímeros S-DVB é antecedida de uma etapa de preparação da matriz, que pode ser através de uma reação de clorometilação ${ }^{[45-47]}$, clorossulfonação ${ }^{[48]}$ ou uma acilação do tipo Friedel Crafts ${ }^{[49]}$, reação com uma amina e finalmente com dissulfeto de carbono em meio alcalino (Esquema da Figura 1).

Roy e colaboradore ${ }^{[50]}$ sintetizaram uma resina com grupos ditiocarbamato via nitração do anel aromático. Após a etapa de nitração e redução química, a resina era reagida com dissulfeto de carbono em meio alcalino. A menor eficiência do material produzido nesse trabalho para o chumbo, em relação aos outros cátions testados, pode ser justificada considerando-se o elevado tamanho desse metal e a proximidade entre o grupo funcional e o suporte. A proximidade entre a matriz e os grupos ativos é função da disposição do grupo nitro, precursor do grupo amino, que posteriormente será modificado pela reação com dissulfeto de carbono. Não foram feitos testes de adsorção de mercúrio, entretanto é possível supor que esse material também retenha uma pequena quantidade desse metal em função da sua semelhança com o chumbo.

Quando da imobilização de um grupo funcional em uma resina polimérica, o impedimento estérico oferecido pela resina pode dificultar a formação de um complexo de geometria 

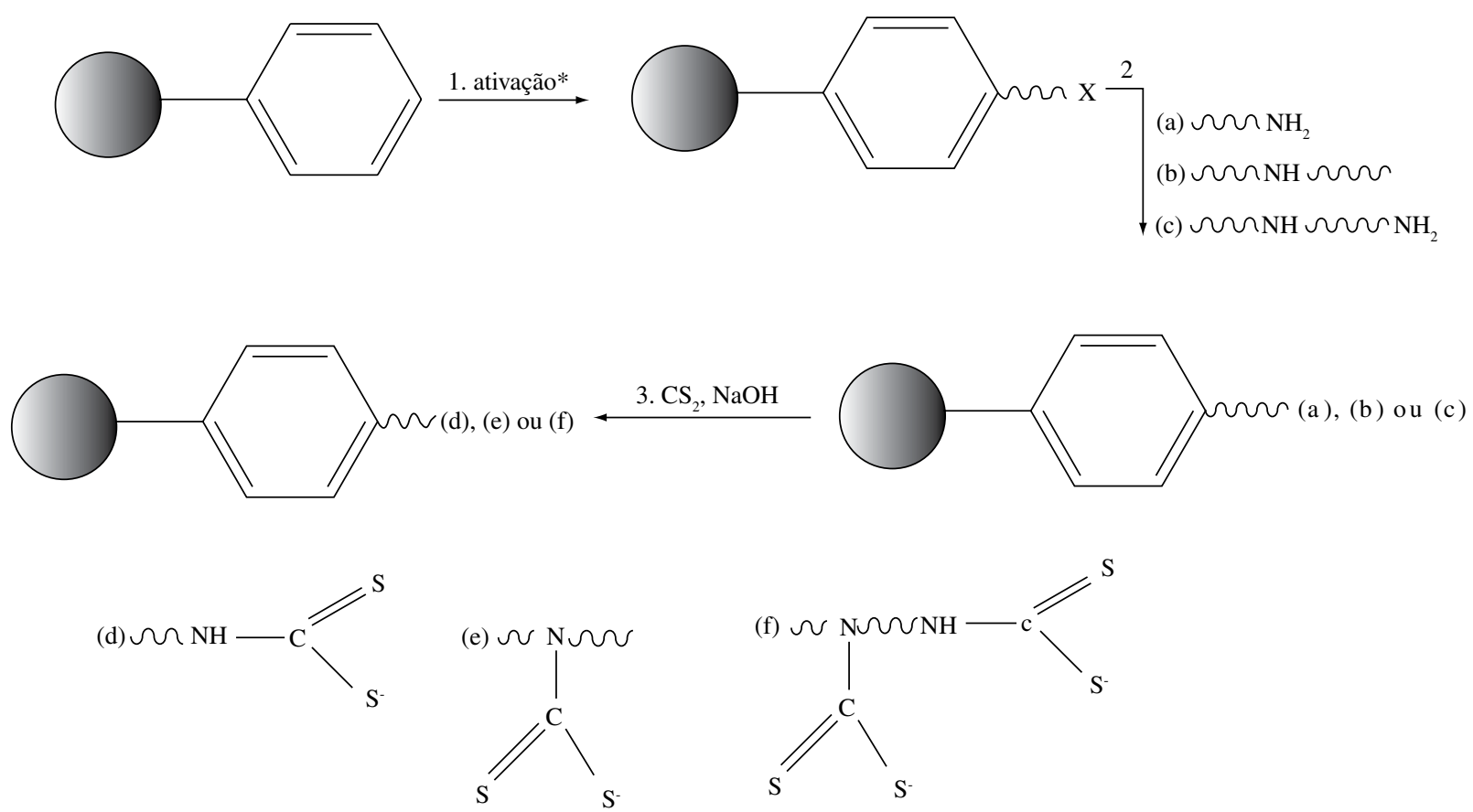

Figura 1. Esquema da introdução de grupos ditiocarbamato em copolímeros S-DVB. 1) ativação *: reação de clorometilação, clorrosulfonação ou acilação de Friedel Crafts; X grupo de saída; 2) reação com uma amina primária ou secundária; e 3) reação com dissulfeto de carbono em meio alcalino.

adequada com o centro metálico. Esse efeito é observado, por exemplo, para resinas contendo grupos ditiocarbamato. Extratores do tipo ditiocarbamato em fase líquida formam complexos, preferencialmente, com ácidos moles, em função da basicidade do átomo de enxofre. A relação estequiométrica entre o metal e grupo complexante é nesses casos 1:2. Entretanto, algumas resinas ditiocarbamato mostram preferência por cátions monovalentes em detrimento dos ácidos moles. A relação 1:1 passa a ser preferível devido à dificuldade dos grupos ditiocarbamato se aproximarem. A aproximação intra ou intermolecular de unidades de ditiocarbamato pode ser conseguida com a utilização de grupos de cadeia longa como precursores dessa função ${ }^{[8,48,51]}$.

Pode ser observado que quando uma amina é usada na preparação de uma resina ditiocarbamato, o tamanho da sua cadeia carbônica tem influência diretamente sobre a capacidade e a seletividade da resina produzida. Resinas ditiocarbamato obtidas a partir de aminas secundárias são geralmente mais eficientes que as obtidas com aminas primárias. Longas cadeias carbônicas atuam como espaçadores e permitem a formação de complexos mais estáveis entre as unidades de ditiocarbamato e cátions moles como chumbo, cádmio e mercúrio $^{[51]}$

A utilização de aminas contendo grupos polares também aumenta a capacidade das resinas ditiocarbamato. Esses grupos permitem uma maior interação com o meio aquoso e, conseqüentemente, maior acessibilidade do íon ao sítio de complexação $^{[49]}$.

A elevada reatividade do óxido de etileno tornam os suportes contendo um anel oxirano, como metacrilato de glicidila, uma boa alternativa para a produção de resinas que- lantes do tipo ditiocarbamato e também para outros tipos de funcionalizações. As resinas obtidas por funcionalização com metacrilato de glicidila contêm na cadeia principal, além do grupo funcional, uma hidroxila derivada da abertura do anel oxirano. Além de promover melhor interação com o meio aquoso é possível também que a hidroxila participe de reações de complexação e por isso contribua para o aumento da capacidade da resina.

No trabalho de Atia e colaboradores ${ }^{[52]}$ uma resina de metacrilato de glicidila e divinilbenzeno foi reagida com etilenodiamina em meio de dimetilformamida para produzir uma resina quelante denominada R-N. A resina R-N foi então tratada com dissulfeto de carbono para a introdução de grupos ditiocarbamato (R-S). Ambos os materiais, R-N e R-S, foram avaliados quanto à capacidade de retenção de cátions $\mathrm{Zn}$ (II), $\mathrm{Cd}$ (II) e $\mathrm{Hg}$ (II) e mostraram maior afinidade por $\mathrm{Hg}$ (II) em relação aos outros dois metais. A resina ditiocarbamato apresentou melhores capacidades de retenção, para os três cátions, do que a resina aminada. Isso pode ser facilmente justificado em função do caráter mais básico do enxofre.

Nos trabalhos de Matew e Pillai ${ }^{[53]}$ e Tiwari e Bajpai ${ }^{[54]}$ no lugar de copolímeros de S-DVB, resinas de poliacrilamida foram sugeridas como suportes para ditiocarbamato.

No trabalho de Matew e Pillai ${ }^{[53]}$, as resinas eram produzidas por uma rota em três etapas. Síntese de suportes com variados graus de reticulação (a partir da reação entre acrilamida e diferentes teores de DVB), transamidação com etilenodiamina e reação com dissulfeto de carbono. O aumento do grau de reticulação das pérolas prejudicou a reação de transamidação e como conseqüência as resinas complexantes obtidas a partir de suportes que continham maiores teores 
de DVB eram menos eficientes. Enquanto a capacidade de retenção da resina ditiocarbamato obtida a partir do suporte com $2 \%$ de DVB era $890 \mathrm{mg} / \mathrm{g}$ para $\mathrm{Hg}(\mathrm{II})$, a capacidade da resina obtida a partir de um outro suporte com $20 \%$ de DVB era cerca de oito vezes menor para esse mesmo íon metálico. Também foram feitos testes de retenção para cobre, níquel, cobalto e zinco, porém as resinas mostraram maior preferência por mercúrio.

Já no trabalho de Tiwari e Bajpai ${ }^{[54]}$ uma resina poliacrilamida comercial era simplesmente tratada com dissulfeto de carbono em meio alcalino para a introdução dos grupos ditiocarbamato. Os testes de retenção feitos para íons de cobre, cobalto, níquel, zinco, mercúrio, chumbo e cério revelaram uma maior preferência da resina pelo primeiro íon. A capacidade de adsorção para os íons mercúrio foi de $5,85 \mathrm{meq} / \mathrm{g}$.

A ditizona (difeniltiocarbazona) é um complexante muito utilizado em métodos colorimétricos de quantificação de íons mercúrio. A sua imobilização em copolímeros estirênicos e piridínicos inicia-se normalmente com uma etapa de clorometilação, seguida de reação com desidroditizona, um produto de oxidação da ditizona, para a formação de um grupo tetrazolio e finalmente uma etapa de redução química para ditizona com solução neutra de ácido ascórbico (Figura 2) ${ }^{[55-58]}$.

A reação direta de copolímeros estirênicos clorometilados com ditizona não é possível devido à tendência da ditizona para sofrer ciclização com haletos de alquila, gerando compostos como 1,3,4 tiodiazolinas ou verdazil ${ }^{[55]}$. Por ser mais nucleofílico, o composto mesoiônico sofre reação de substituição mais rapidamente com o grupo clorometilênico preso ao suporte do que a ditizona. Entretanto, são ne- cessários longos tempos de reação na etapa de redução para ditizona.

Assim como para ditiocarbamato, a formação de ditizonatos com cátions bivalentes ocorre segundo a relação estequiométrica 1:2 entre o metal e a função $0^{[4]}$. O impedimento estérico oferecido pela matriz sólida dificulta a aproximação dos grupos ditizona para formação de quelatos e como consequiência, os valores de capacidade das resinas ditizona são menores que os esperados. Uma mudança na rota de síntese com a introdução de um grupo de cadeia longa antes da reação dos suportes com desidroditizona poderia favorecer a formação de sais, mesmo com cátions grandes como mercúrio, entretanto, não foram encontrados trabalhos que tratem do uso de espaçadores entre os grupos ditizona e o suporte.

Alguns trabalhos também tratam do uso de um copolímero hidrofílico à base de dimetacrilato de glicol etilênico metacrilato de 2-hidroxietila (EGDMA-HEMA) como suporte para ditizona ${ }^{[59,60]}$. A reação de funcionalização deste material era feita diretamente através de reação com ditizona em meio alcalino. No primeiro trabalho, foram feitos testes de retenção para cátions de cádmio, cromio, chumbo e mercúrio. Os resultados encontrados revelaram uma preferência da resina para chumbo. Já no outro trabalho foi avaliada a capacidade da resina de adsorver íons mercúrio e também espécies organocloradas, cloreto de metil e de etilmercúrio. Os valores de capacidade foram respectivamente 138, $221 \mathrm{e}$ $207 \mathrm{mg} / \mathrm{g}$ para essas três espécies.

TMR (Remoção Total de Mercúrio) é o nome da primeira resina comercial obtida a partir da funcionalização de copolímeros estirênicos reticulados com grupos mercaptan (denominação dada ao grupo $\mathrm{SH}$ em função de sua capacidade de

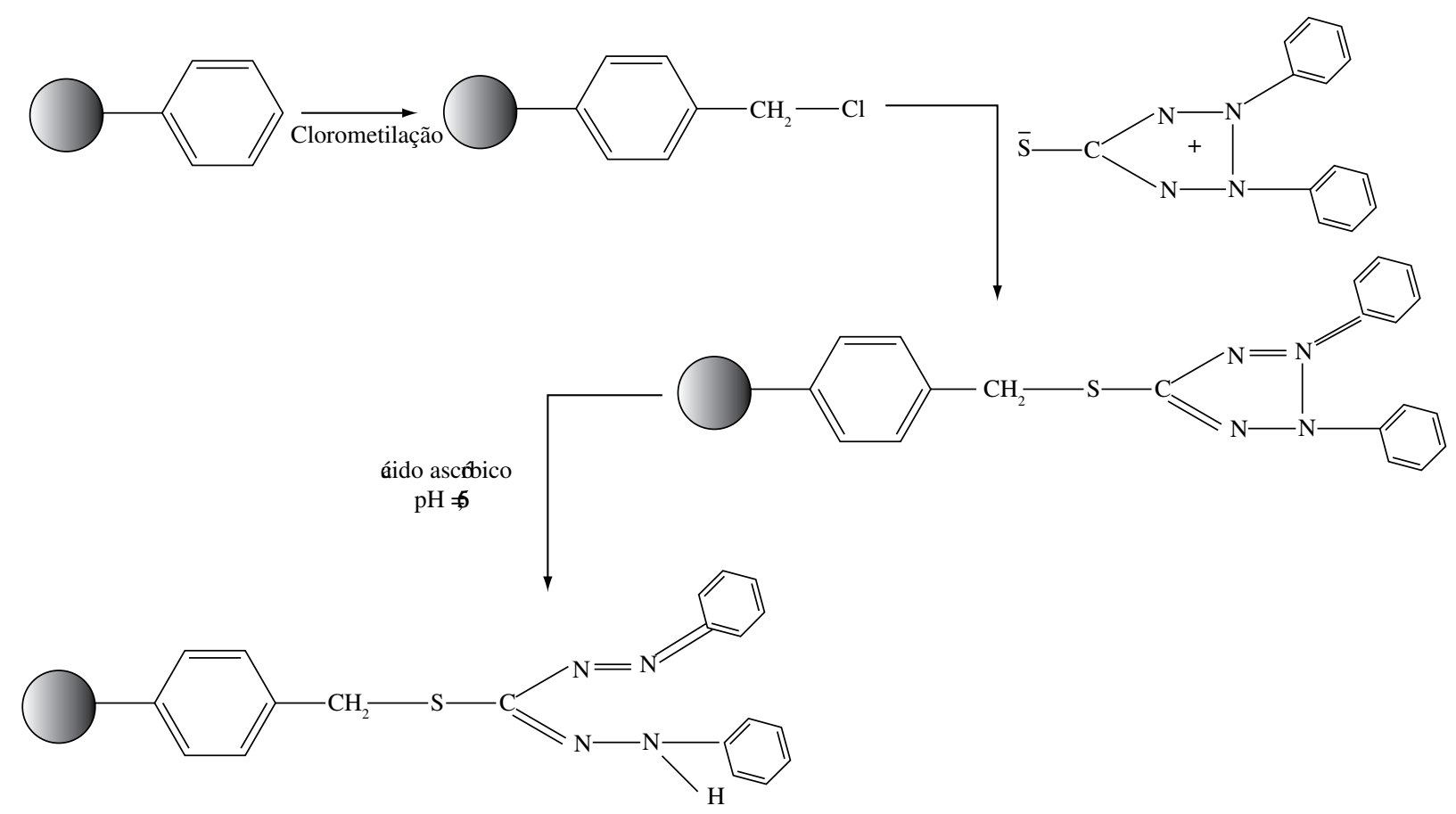

Figura 2. Funcionalização de copolímeros estirênicos com ditizona. 
reagir com mercúrio). Esse material foi primeiro produzido pela Akzo Zout em 1976, sendo posteriormente fabricado pela Duolite (Duolite GT-73) e mais tarde pela Rohm and Haas (Amberlite GT-73) ${ }^{[61,62]}$.

Ao longo dos anos, diversas rotas vêm sendo sugeridas para a introdução de grupos mercaptan em resinas estirênicas. O procedimento geralmente empregado para a introdução desses grupos em anéis aromáticos é realizado em duas etapas principais, a introdução de um grupo tioalquila ou tioacila (grupo protetor) seguida de uma reação de hidrólise para liberação dos grupos tióis. O uso de um grupo protetor se faz necessário em função da possibilidade de oxidação dos grupos tióis e da formação de pontes dissulfeto.

Uma das propostas de Fréchet e colaboradores ${ }^{[63]}$ para a síntese de uma resina estirênica reticulada, baseada em um trabalho de Okawara e colaboradores publicado anos antes ${ }^{[64]}$, parte da reação de um copolímero S-DVB, clorometilado, com tiouréia e hidrólise alcalina do sal de tiourônio formado. Slovák e colaboradores ${ }^{[65]}$ e Lezzi, Cobianco e Rogero ${ }^{[66]}$ também sugerem a reação dos seus produtos com tiouréia para formação do sal correspondente nas etapas finais de suas propostas de síntese de resinas tiol.

No trabalho de Slovák ${ }^{[65]}$, géis hidrofílicos de metacrilato de glicol etilênico (Spheron) são reagidos com epicloridrina e com tiouréia e o produto obtido é hidrolizado para a liberação dos grupos $\mathrm{SH}$ correspondentes. O material produzido mostra uma vasta gama de aplicações, sendo capaz de adsorver diversos íons metálicos, inclusive mercúrio. São formados complexos tão fortes com mercúrio, bismuto, antimônio e arsênio que a adsorção desses metais é independente do $\mathrm{pH}$ do meio. Além disso, os géis "Spheron thiol" mostram uma cinética rápida de retenção de traços de mercúrio a partir soluções ácidas.

Lezzi, Cobianco e Rogero. ${ }^{[6]}$ sugeriram a introdução de cadeias espaçadoras de poli(glicol etilênico) entre os copolímeros S-DVB e o grupo tiol como uma alternativa para aumentar a eficiência dessas resinas. A rota de síntese sugerida para a obtenção desse material consiste de quatro etapas principais. Graftização de cadeias de poli(glicol etilênico) de diferentes comprimentos nos copolímeros de S-DVB clorometilados; bromação dos grupos hidroxila com tribrometo de fósforo e reação com tiouréia, seguida de hidrólise alcalina dos sais iso-tiourônios formados. As resinas produzidas foram avaliadas quanto à capacidade de complexação de mercúrio, cádmio e chumbo. Os resultados encontrados revelaram que o aumento do comprimento das cadeias de poli (glicol etilênico) favorecia a reação de complexação e que as resinas produzidas apresentavam maior afinidade para mercúrio em relação aos outros dois metais.

Uma resina tiol também foi produzida a partir da reação de um suporte hidrofílico sulfurado análogo aos géis Spheron com uma solução etanólica de hidrogenossulfato de potássio. Através da reação de metacrilato de glicidila com tiocianato de amônio o oxigênio do anel epóxi foi substituído por enxofre. O monômero obtido foi polimerizado e a resina resul- tante foi reagida com o hidrogenossulfato de potássio para liberar os grupos tióis. A resina tiol produzida nesse trabalho apresentou valores de capacidade de adsorção da ordem de 2 a $3 \mathrm{mmol} \mathrm{de} \mathrm{Ag}^{+} \mathrm{e} \mathrm{Hg}^{2+}$ por grama de resina; a capacidade máxima foi conseguida em $\mathrm{pH}$ próximo de $6^{[67]}$.

Dujardin, Cazé e Vroman ${ }^{[61]}$ propuseram duas rotas de síntese para a introdução de grupos tiol em copolímeros de S-DVB, sendo o grupamento tioacetato o precursor dessa função. A primeira proposta trata da síntese de monômeros funcionalizados e subseqüente polimerização. A reação de substituição de bromo em p-bromoestireno por tioacetato de potássio acontecia com baixos valores de rendimento. A nitração do anel favorecia a reação de bromação, entretanto, a ocorrência de reações secundárias com o solvente impediam uma extração eficiente do monômero e por isso essa rota foi abandonada. A segunda proposta era baseada na funcionalização dos suportes preparados anteriormente. As modificações químicas consistiam de quatro passos principais: bromação da matriz polimérica, nitração, substituição do bromo pelo tioacetato e, finalmente, uma reação de hidrólise para liberação dos grupos SH. As resinas produzidas eram comparadas, quanto à capacidade de retenção de mercúrio, com uma resina tiol produzida pela Rohm \& Haas. Os resultados encontrados demonstram que ambos os materiais eram eficientes na captação desse íon metálico, presente em níveis traço em rejeitos industriais. Os testes em água industrial revelaram que a concentração de mercúrio era reduzida de 5 a 10 ppm para menos de $10 \mathrm{ppb}$.

Também foram descritas duas rotas de síntese para a introdução de grupos tiol em resinas XAD-4 (copolímeros S-DVB com 10\% de DVB) baseadas na reação desses suportes com ácido tioglicólico ${ }^{[68,69]}$. No primeiro trabalho, os suportes sofriam acilação Friedel-Crafts com anidrido acético, catalisada por cloreto de alumínio. O produto era oxidado a ácido com permanganato de potássio e hidróxido de sódio, reagido com 1,6-hexanodiol e finalmente com o ácido. $\mathrm{Na}$ segunda proposta a reação das resinas XAD-4 com ácido tioglicólico era antecedida das etapas de esterificação dos anéis estirênicos com formaldeído, anidrido acético e cloreto de zinco e, de transesterificação com metanol e ácido clorídrico.

Qu e colaboradores ${ }^{[70,71]}$ prepararam uma série de resinas complexantes por meio da reação de copolímeros S-DVB clorometilados com 2-mercaptoetanol. No primeiro trabalho ${ }^{[70]}$, as resinas mercaptoetanol eram reagidas com acetona ou ácido acético, na presença de peróxido de hidrogênio. Antes do tratamento com acetona ou ácido, as resinas retinham uma maior quantidade de mercúrio em detrimento de uma série de outros íons. Porém, após a reação com acetona, a capacidade de adsorção para mercúrio era reduzida de 2,80 para $1,45 \mathrm{mmol} / \mathrm{g}$ e as resinas passavam a adsorver $\mathrm{Pb}^{2+} \mathrm{em}$ maior proporção. Após a reação com ácido, a capacidade de adsorção para $\mathrm{Hg}^{2+}$ era diminuída para $0,27 \mathrm{mmol} / \mathrm{g}$ e a retenção de $\mathrm{Cu}^{2+}$ era preferencial. Já no segundo trabalho ${ }^{[71]}$, as resinas com mercaptoetanol eram 
reagidas com cloreto de fenilsulfonila e finalmente com etanolamina, etilenodiamina, trietilenodiamina ou tetraetilenodiamina para produzir quatro materiais diferentes. A resina obtida a partir da reação com trietilenotetramina era mais eficiente para remoção de quase todos os cátions avaliados, inclusive íons mercúricos. As quatro resinas produzidas eram mais eficientes na remoção de íons chumbo.

$\mathrm{Qu}$ e colaboradores ${ }^{[72]}$ também sugerem a funcionalização de copolímeros S-DVB com 2,5-dimercapto-1,3,4tiodiazol (bismutiol, BMT) para a síntese de uma resina adsorvente de mercúrio. A determinação do teor de cloro e enxofre, por análise elementar, revelou que pouco mais da metade dos grupo $\mathrm{Cl}$ eram substituídos por grupos bismutiol. O grau de conversão incompleto foi justificado com base na formação de uma estrutura reticulada entre o anel heterocíclico BMT (com anions tiol em cada uma das extremidades) e dois grupos clorometilênicos. Os testes de retenção feitos para mercúrio revelaram que o aumento da temperatura facilitava o processo de adsorção e o modelo de Langmuir era melhor que o modelo de Freundlich para descrever a variação da capacidade da resina com a temperatura. A resina era melhor regenerada com uma solução de $2 \%$ de tiouréia em $\mathrm{HCl} 0,1 \mathrm{M}$ e apresentava valores de capacidade da ordem de 0,6 a $0,7 \mathrm{mmol} / \mathrm{g}$ em cinco ciclos de adsorção-dessorção, o que demonstra que ela pode ser reutilizada por várias vezes sem uma mudança considerável na capacidade de adsorção.
Outras tentativas de introduzir grupos complexantes sulfurados em resinas estirênicas macroporosas foram feitas por Mondal e Das ${ }^{[73]}$ e por Guo e colaboradores ${ }^{[74]}$.

Mondal e Das ${ }^{[73]}$ sugerem uma metodologia para pré-concentração e determinação de mercúrio e metilmercúrio em níveis traço, baseada na separação em fase sólida, usando uma resina $\mathrm{S}$-DVB com grupos 1,2-bis (o-aminofeniltio)etano. Os estudos de capacidade de adsorção e dessorção desses compostos mostram que a resina se liga mais fortemente ao íon mercúrico que ao composto metilado. $\mathrm{O}$ etanol é o solvente mais adequado para a melhor eluição de metilmercúrio, já o íon mercúrico é melhor dessorvido quando se usa uma mistura de $10 \%$ de tiouréia em $\mathrm{HCl}, 1 \mathrm{M}$.

Guo e colaboradores ${ }^{[74]}$ propuseram um novo método para a determinação de diferentes íons divalentes em matrizes variadas, utilizando um plasma indutivamente acoplado à espectrometria de emissão atômica. Uma resina XAD-4 tratada com 2-aminoacetiltiofenol era usada na etapa de pré-concentração dos analitos. As resinas sofriam nitração, redução e diazotação antes da introdução do grupo funcional. A síntese desse grupo era realizada por meio de reação entre 2-aminotiofenol e etanol em meio de carbonato de sódio e anidrido acético. O limite de detecção de mercúrio por ICP-AES era de $0,23 \mu \mathrm{mol} / \mathrm{L}$ e o desvio padrão relativo das determinações era menor que $10 \%$.

Resinas quelantes contendo compostos heterocíclicos nitrogenados têm se mostrado seletivas para metais de

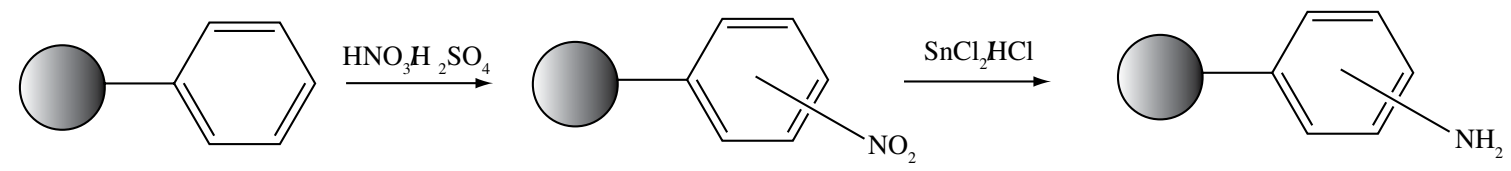

$\mathrm{X}$ pode ser por eømplo:<smiles>c1c[nH]cn1</smiles>

benimidaøl<smiles>c1ccc2[nH]cnc2c1</smiles>

mercaptopurina<smiles>Sc1ncnc2[nH]cnc12</smiles>

(a) diaøtação

(b) ligação com um composto bterocélico nitrogenado $\mathrm{X}$

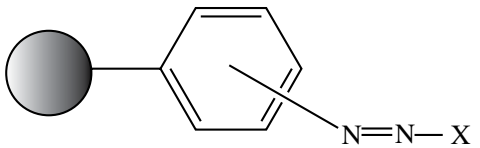

Figura 3. Funcionalização de copolímeros S-DVB com compostos heterocíclicos nitrogenados. 
transição, mais especificamente prata, em função do menor volume desse cátion ${ }^{[75-77]}$. A imobilização desses grupos em copolímeros estirênicos reticulados ocorre normalmente, via ligação $-\mathrm{N}=\mathrm{N}-$ entre os anéis aromáticos e a função (Figura 3). Os valores de capacidade de retenção desses compostos para cátions $\mathrm{Hg}^{2+}$ e outros cátions volumosos são quase sempre muito baixos em função de fatores estéricos, ou seja, da impossibilidade dos anéis heterocíclicos assumirem uma geometria adequada para complexar esses cátions. Deve ser considerado também, que os compostos nitrogenados são tidos como bases de fronteira com características intermediárias entre uma base mole e uma base dura e por isso não tem tanta afinidade por ácidos moles. A presença de um grupo tiol nesses anéis nitrogenados, como no caso da mercaptopurina, aumenta a capacidade de retenção para mercúrio, porém as resinas funcionalizadas com esse grupo funcional ainda retém prata preferencialmente ${ }^{[77]}$.

Resinas hidrofílicas baseadas em metacrilato de glicidila ou no seu análogo sulfurado também foram usadas como suportes para diferentes ligantes azo, pirazol, imidazol, 1,2,4-triazol e tetrazol. Esses materiais continham, além do composto heterocíclico nitrogenado, uma hidroxila ou um grupo tiol na cadeia principal derivados da abertura do anel oxirano ou tiurano. Os testes de retenção para cloretos de cobre, níquel, cobalto, zinco e cádmio revelaram que os materiais obtidos a partir do monômero contendo o anel tiurano eram mais eficientes do que os que continham a hidroxila na cadeia principal. A retenção de cobre era preferencial para as duas resinas; não foram feitos testes de retenção para prata e mercúrio $^{[78]}$.

Outro grupo funcional classicamente usado na adsorção de cátions metálicos são os éteres coroa. Os éteres coroa são poliéteres monocíclicos que apresentam a propriedade de reconhecer seletivamente cátions metálicos. $\mathrm{O}$ tipo de cátion a ser retido irá depender do tamanho e da rigidez do anel. Uma série de heteroátomos também pode ser adicionada ao ciclo para aumentar a capacidade desse complexante por um ou outro metal. Assim, quando o objetivo é a retenção de mercúrio, ou qualquer outro ácido mole, o mais recomendável é que se tenha átomos de enxofre junto do grupo éter coroa ou compondo a estrutura do anel, por conta da afinidade enxofre-mercúrio. Foi assim, por exemplo, que Baumann e colaboradores ${ }^{[79]}$ produziram bons materiais para captação de mercúrio. Os autores sintetizaram resinas do tipo tioéter, com anéis de diferentes tamanhos (quatro ou cinco átomos de enxofre), e os imobilizaram em copolímeros S-DVB.

Resinas contendo grupos uréia ou os análogos sulfurados desses grupos também são materiais bastante estudados para retenção de metais tóxicos. Zuo e Muhammed ${ }^{[80]}$ graftizaram tiouréia em resinas estirênicas comerciais e produziram materiais com alta capacidade de adsorção de mercúrio a partir de soluções cloroácidas. As resinas também tinham boa seletividade para a retenção de mercúrio sobre cádmio e zinco. Bicak e colaboradores ${ }^{[81]}$ introduziram grupos uréia vicinais em um terpolímero de metacrilato de metila, metacrilato de glicidila e divinilbenzeno visando a produção de um material específico para retenção de íons mercúricos. A síntese desse material seguiu as etapas de reação do terpolímero com um excesso de trietilenotetramina, tratamento da resina aminada com ácido clorídrico e finalmente reação do produto com uma solução de cianeto de potássio. Essa resina apresentou uma capacidade em íons mercúricos de $6,7 \mathrm{mmol} / \mathrm{g}$ e não formava complexos com metais alcalinos terrosos e nem com outros metais de transição.

A seletividade absoluta para um determinado íon nem sempre é considerada uma característica vantajosa, principalmente se levarmos em conta que o mercado potencial de resinas específicas é relativamente baixo em função das suas pequenas possibilidades de uso, que tornam o custo unitário desses produtos alto. Porém, em determinadas situações, como quando o íon metálico é precioso, a produção de uma resina específica é compensatória. Resinas seletivas para mercúrio são também preferenciais em função da importância desse metal, no que diz respeito à sua vasta aplicação em diversas áreas ${ }^{[82]}$.

A redução da basicidade do átomo de nitrogênio, em função da presença da carbonila, torna o grupamento amida pouco capaz de participar de reações de coordenação com outros íons metálicos, porém extremamente seletivo para mercúrio, ácido altamente capaz de sofrer reações de complexação. Testes que avaliaram a eficiência de materiais alternativos, tais como celulose e casca de coco, e de suportes orgânicos funcionalizados com poliacrilamida revelaram uma alta especificidade para mercúrio em detrimento de outros íons metálicos tóxicos normalmente também presentes nos rejeitos industriais $^{[83-90]}$.

A introdução de cadeias de poliacrilamida em copolímeros S-DVB surge como uma proposta promissora não somente de criação de um material seletivo para mercúrio e compostos mercuriais, mas também de desenvolvimento de um material com alta capacidade. Assim como quando cadeias espaçadoras são colocadas entre a matriz e o grupo complexante, a graftização dessas cadeias hidrofílicas em suportes particulados minimiza o impedimento estérico oferecido pela matriz e propicia a formação de complexos de geometria adequada com íons volumosos como os íons mercúricos. A introdução dos "grafts"de poliacrilamida nos suportes proporciona o desenvolvimento de uma condição reacional pseudo-homogênea e valores de capacidade de complexação tão altos quanto os apresentados por complexantes em fase homogênea.

A introdução de cadeias de poliacrilamida em copolímeros estirênicos vem sendo realizada via polimerização radicalar, utilizando um sistema de oxi-redução. A oxidação de um dado grupo funcional preso ao copolímero leva à formação de um macrorradical, que em uma etapa subseqüente é capaz de iniciar a polimerização da acrilamida (Figura 4). Dois tipos principais de agentes oxidantes têm sido usados para a formação de radicais livres, nitrato cérico amoniacal e um sistema vivo formado por brometo cúprico e tetrame- 
tilenodiamina (TMEDA) (polimerização por transferência de átomo). $\mathrm{O}$ emprego desse último sistema proporciona um maior controle da etapa de graftização e menores teores de sub-produto (homopolímero). Entretanto, a necessidade de um controle mais rigoroso das condições reacionais é o inconveniente desse método ${ }^{[87-90]}$.

A introdução de cadeias de poliacrilamida em suportes poliméricos pré-fabricados, especialmente copolímeros S-DVB, pode ser considerado o melhor recurso para a produção de uma resina seletiva e eficiente para a remoção de mercúrio. Os materiais produzidos por essa rota retêm exclusivamente mercúrio. A maioria deles é eficiente na remoção de traços desse metal a partir de soluções diluídas e a sua cinética de retenção é rápida.

O interesse no desenvolvimento de resinas S-DVB graftizadas com poliacrilamida justifica-se pela afinidade química amida-mercúrio e pelo domínio da tecnologia de síntese e baixo custo desse suporte. As reações de modificação dos copolímeros S-DVB podem ser facilmente entendidas e controladas em função do grande número de estudos correlacionando porosidade e condições de síntese. Entretanto, assim como acontece para a introdução de outras funções nesses copolímeros, são muitas as reações seqüenciais até que o objetivo seja atingido.

A maioria das propostas de imobilização de grupos complexantes em copolímeros S-DVB parte de uma reação de preparação dos anéis benzênicos, mais comumente através de uma reação de clorometilação ou nitração, e diversas ou- tras reações até a introdução do grupo funcional desejado. Rotas muito extensas, com grande número de passos, são dispendiosas, produzem um grande volume de rejeitos e podem conduzir a uma mistura de grupos funcionais nos produtos finais devido a substituições incompletas em cada etapa. Entretanto, as funcionalizações conseguidas de maneira mais direta conduzem, em determinadas situações, à produção de materiais pouco eficientes para metais de grande raio atômico em função do impedimento estérico oferecido pela matriz polimérica à formação de complexos de geometria adequada com esses metais.

A introdução de grupos funcionais em suportes hidrofílicos é feita geralmente em poucas etapas devido, quase sempre, à presença de um grupo reativo em pelo menos um dos monômeros, como é o caso do metacrilato de glicidila. Além disso, o uso de suportes hidrofílicos pode proporcionar a criação de resinas muito eficientes devido à alta probabilidade de contato entre o grupo complexante e o íon, justificada pela capacidade de inchamento do suporte em meio aquoso. Contudo, os monômeros hidrofílicos são, em sua maioria, dispendiosos, valendo mais a pena a introdução de mais uma ou duas etapas para se alcançar a funcionalização desejada de um copolímero S-DVB, que utilizar monômeros desse tipo.

Alguns trabalhos tratam também da polimerização de monômeros já contendo o grupo complexante. Para a síntese de resinas amida, por essa rota, monômeros acrílicos ou metacrílicos, ou ainda derivados desses compostos, são reagidos com monômeros vinílicos contendo um anel heterocíclico ni-
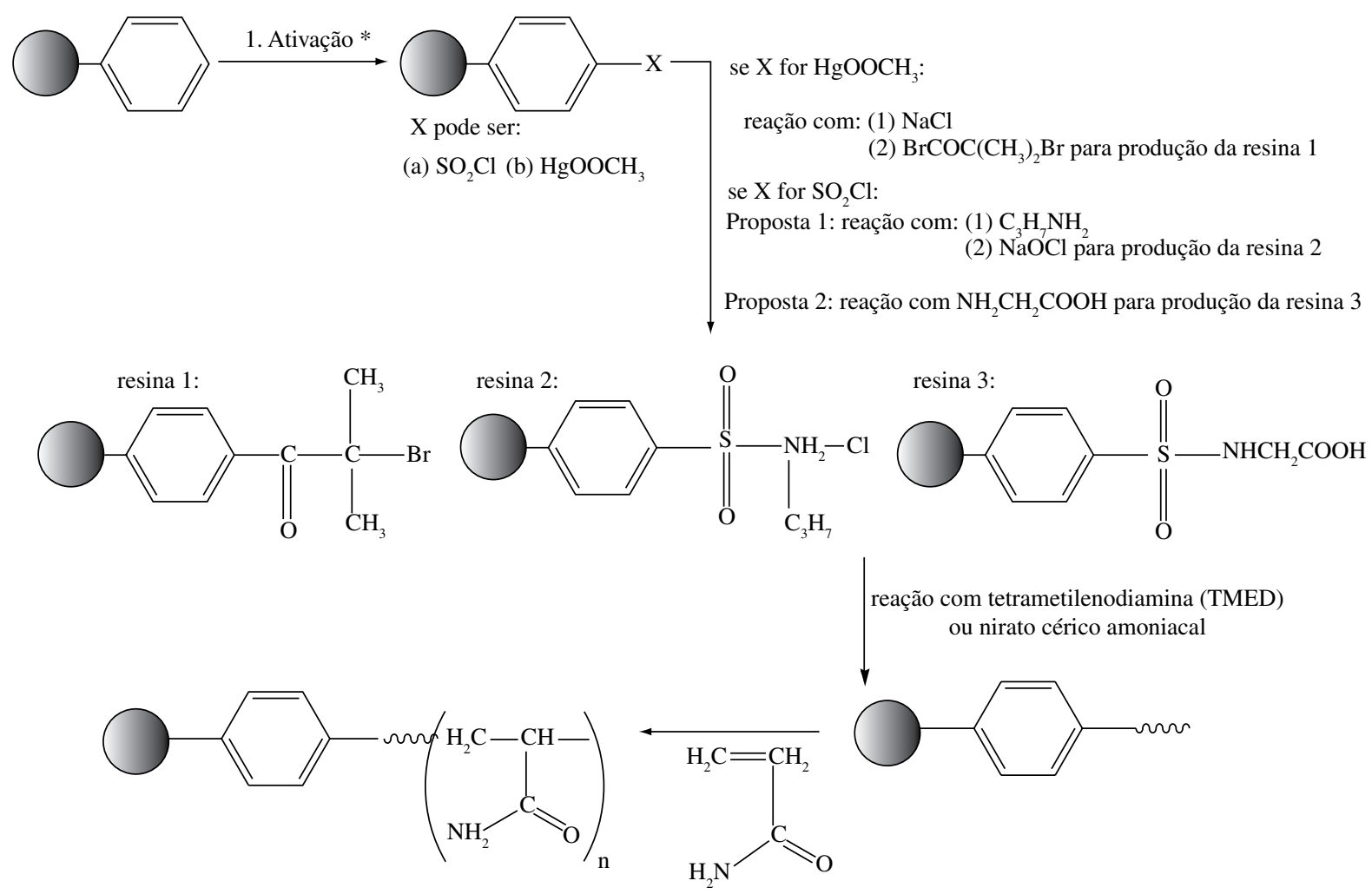

Figura 4. Mecanismo de graftização de cadeias de poliacrilamida em copolímeros estirênicos e piridínicos. 
trogenado (mais freqüentemente N-vinilimidazol). N-N-metileno-bis-acrilamida é o agente de reticulação mais adotado e quase sempre o iniciador escolhido para essas reações é persulfato de amônio ${ }^{\text {[91-93]. }}$.

Muito embora a polimerização de monômeros funcionalizados conduza à formação de materiais mais limpos que os produzidos de forma indireta pela modificação de matrizes pré-formadas esta última forma de síntese ainda é preferida devido, principalmente, ao custo elevado dos monômeros funcionalizados. A dificuldade de se obter pérolas esféricas pela polimerização de monômeros funcionalizados também é uma desvantagem, principalmente, se as resinas complexantes forem preencher uma coluna cromatográfica.

A impregnação de suportes pré-produzidos com agentes complexantes também é uma forma mais direta de sintetizar resinas complexantes. $\mathrm{O}$ interesse em resinas impregnadas para a remoção de íons metálicos advém, principalmente, do fato desses materiais serem facilmente preparados. Porém, o número reduzido de ciclos com boa eficiência, devido à possibilidade de lixiviação do agente complexante, torna esse tipo de rota pouca atrativa economicamente ${ }^{[8]}$.

\section{Conclusão}

De acordo com o que foi exposto, pode-se concluir que as resinas complexantes são mais freqüentemente sintetizadas de forma indireta, a partir da imobilização de grupos complexantes em copolímeros de estireno e divinilbenzeno (S-DVB). O baixo custo, a estabilidade química e principalmente o domínio da tecnologia de síntese são as principais justificativas para o emprego de copolímeros S-DVB como suportes. Já quanto ao grupo quelante, a sua escolha quase sempre leva em consideração a teoria de Pearson. De acordo com essa teoria os melhores complexantes para mercúrio contêm grupos básicos moles em sua estrutura. Dentre os grupos complexantes já avaliados para a adsorção de mercúrio, os sulfurados são os mais estudados em função da basicidade do átomo de enxofre.

Resinas seletivas para mercúrio são obtidas a partir da graftização de cadeias de poliacrilamida em copolímeros SDVB. Essas resinas apresentam, quase sempre, altos valores de capacidade de adsorção em função das características hidrofílicas da acrilamida. As cadeias polares de poliacrilamida permitem uma melhor interação com o meio aquoso e a maximização do contato entre os íons metálicos e os grupos complexantes.

A maioria das rotas para a preparação de resinas complexantes é constituída de um grande número de etapas e por esse motivo são dispendiosas e produzem um grande volume de rejeitos. Embora a polimerização de monômeros funcionalizados seja uma forma mais direta de síntese de resinas complexantes, quase não é utilizada devido ao custo elevado desses monômeros. A impregnação é também uma maneira mais direta e simples de produção de resinas complexantes, mas também não é adequada pois há a possibilidade de lixi- viação do agente complexante. Assim, o grande desafio no que diz respeito à síntese de resinas complexantes é o desenvolvimento de rotas de síntese mais curtas, que possibilitem a imobilização do grupo quelante em um menor número de etapas, e que conduzam à formação de materiais eficientes.

É de grande valia o desenvolvimento de uma rota de síntese que leve a funcionalizações mais diretas de copolímeros S-DVB com grupos complexantes para o mercúrio. A redução do número de etapas pode abaixar o custo de produção das resinas e torná-las mais acessíveis às indústrias que utilizam esse metal em seus processos. $\mathrm{O}$ ganho ecológico não será somente em termos de redução dos níveis de mercúrio das águas, mas também de redução da quantidade de resíduos gerados durante a síntese das resinas.

\section{Agradecimentos}

Ao CNPq, à FAPERJ e à CAPES pelo apoio financeiro e a Ixthá Hasselmann Valeriano, nossa querida aluna de iniciação científica, pela ajuda com os esquemas de síntese.

\section{Referências Bibliográficas}

1. Engel, G. T. - "Mercury", in: Encyclopedia of Chemical Technology, Kirk Othmer (ed.), Interscience Publishers, Jonh Wiley \& Sons, Inc., New York (1967).

2. Greenwood, W. N. \& Earnshaw, A. - "Chemistry of the Elements", Pergamon Press, Cambridge (1994).

3. Micaroni, R. C. C. M.; Bueno, M. I. M. S. \& Jardim, W. F. - Quim. Nova, 23, p.487 (2000).

4. Azevedo, F. A. "Toxicologia do mercúrio", RiMa, São Carlos (2003).

5. Daher, V. - Ciência Hoje, 26, p.46 (1999).

6. Marins, R. V.; de Paula Filho, F. J.; Maia, S. R. R.; Lacerda, L. D. \& Marques, W. S. - Quim. Nova, 27, p.763 (2004).

7. Lanças, F. M. - "Extração em Fase Sólida", RiMa, São Carlos (2004).

8. Teixeira, V. G.; Coutinho, F. M. B. \& Gomes, A. S. Quim. Nova, 27, p.27 (2004).

9. Sahni S. K. \& Reedijk, J. - Coord. Chem. Rev. 59, p.1 (1984).

10. Xu, Z.; Zhang, Q. \& Fang, H. H. P. - Crit. Rev. Env. Sci. Technol., 33, p.363 (2003).

11. Rabelo, D. \& Coutinho, F. M. B. - Polym. Bull., 33, p.479 (1994).

12. Rabelo, D. \& Coutinho, F. M. B. - Polym. Bull., 33, p.487 (1994).

13. Rabelo, D. \& Coutinho, F. M. B. - Eur. Polym. J., 30, p.675 (1994).

14. Rabelo, D.; Coutinho, F. M. B. - Macromol. Symp., 84, p.341 (1994). 
15. Rabelo, D.; Coutinho, F. M. B.; Barbosa, C. C. R. \& Rezende, S. M. - Polym. Bull., 34, p.621 (1995).

16. Coutinho, F. M. B.; Neves, M. A. F. S. \& Dias, M. L. J. Appl. Polym. Sci., 65, p.1257 (1997).

17. Coutinho, F. M. B.; La Torre, M. L. \& Rabelo, D. Eur. Polym. J., 34, p.805 (1998).

18. Coutinho, F. M. B.; Alves, G. M.; Neves, M. A. F. S.; Dias, M. L. \& Chagas, B. S. Macromol. Symp., 151, p.399 (2000).

19. OKay, O. - Prog. Polym. Sci., 25, p.711 (2000)

20. Coutinho, F. M. B.; Neves, M. A. F. S. \& Dias, M. L. - Macromol. Symp., 27, p.189 (2002)

21. Coutinho, F. M. B.; Cunha, L. \& Gomes, A. S. - Polímeros: ciência e Tecnologia, 14, p.31 (2004).

22. Coutinho, F. M. B.; Souza, R. R. \& Gomes, A. S. - Eur. Polym. J., 40, p.1525 (2004).

23. Colloids and Surfaces A: Phys. Eng. Asp., 161, p.259 (2000).

24. Leyden, D. E. \& Luttrell, H. - Anal. Chem., 47, p.1612 (1975).

25. Cestari, A. R. \& Airoldi, C. - J. Braz. Chem. Soc., 6, p.291 (1995).

26. Cestari, A. R. \& Airoldi, C. - J. Colloid Interface Sci., 195, p.338 (1997).

27. Mahmoud, M. E. - Anal. Chim. Acta, 398, p.297 (1999)

28. Venkatesan, K. A.; Srinivasan. \& Vasudeva Rao, P. R. Sep. Sci. Technol., 37, p.1417 (2002).

29. Venkatesan, K. A.; Srinivasan. \& Vasudeva Rao, P. R. - J. Radioanal. Nucl. Chem., 256, p.213 (2003).

30. Olkhovyk, O.; Antochshuk, V. \& Jaroniec, M. - Colloids Surf., A, 236, p.69 (2004)

31. Füßler, R.; Schäfer, H. \& Seubert, A. - Anal. Bioanal. Chem., 372, p.705. (2002).

32. Pearson, R. G. - J. Am. Chem. Soc., 85, p.3533, (1963).

33. Dupont, J. - "Química Organometálica - Elementos do Bloco d", Bookman, Porto Alegre (2005).

34. Camel, V. - Spectrochim. Acta, Part B, 58, p.1177 (2003).

35. Lin, L-C. \& Juang, R-S. - Chem. Eng. J., 112, p.211 (2005).

36. Seggiani, M.; Vitolo \& S. D'Antone, S. - Hydrometallurgy, 81, p.9 (2006).

37. Gode, F. \& Pehlivan, E. - J. Haz. Mat., 100, p.231 (2003).

38. Saegusa, T.; Kobayashi, S. \& Yamada, A. - J. Appl. Polym. Sci., 21, p.2481 (1977).

39. Sun, C.; Qu, R.; Ji, C.; Wang, Q.; Wang, C.; Sun, Y. \& Cheng, G. - Eur. Polym. J., 42, p.188 (2006).
40. Ahuja, M.; Rai, A. K. \& Mathur, P. N. - Talanta, 43, p.1955 (1996).

41. Mazidji, C. N.; Koopman, B. \& Bitton, G. - Wat. Sci. Tech., 26, p.189 (1992).

42. Rengan, K. \& Su, B-C. - J. Radioanal. Nucl. Chem., 262, p.175. (2004).

43. Fritz, J. S.; Freeze, R.; Thornton, M. J. \& Gjerde, D. T. - J. Chromatogr., A, 739, p.57 (1996).

44. Dingman, J. F.; Gloss, K. M.; Milano, E. A. \& Siggia, S. - Anal. Chem., 46, p.774 (1974).

45. Hiratani, K.; Onishi, Y. \& Nakagawa, T. - J. Appl. Polym. Sci., 26, p.1475 (1981).

46. Wagner, C. K.; Hall, G.; Riegel, B.; De Virgilio, J.; Kamath, V. \& Germann, G. - J. Appl. Polym. Sci., 31, p. 1797 (1986).

47. Matew, B. \& Pillai, V. N. R. - Eur. Polym. J. 1994, 30, 61 .

48. Huang, S-P.; Franz, J.; Arnold, E. H.; Devenyl, J. \& Fish, R. H. - Polyhedron, 15, p.4241 (1996).

49. McClain, A. \& Hsieh, Y-L. - J. Appl. Polym. Sci., 92, p.218 (2004).

50. Roy, P. K.; Rawat, A. S. \& Rai, P. K. - Talanta, 59, p.239 (2003).

51. Cobianco, S.; Lezzi, A. \& Scotti, S. - React. Funct. Polym, 43, p.7 (2000).

52. Atia, A. A.; Donia, A. M. \& Yousif, A. M. - React. Funct. Polym., 56, p.75 (2003).

53. Matew, B. \& Pillai, V. N. R. - Polym. Bull., 26, p.603 (1991).

54. Tiwari, S. \& Bajpai, A. - React. Funct. Polym., 64, p.47 (2005).

55. Grote, M.; Kettrup, A. - Anal. Chim. Acta, 172, p.223 (1985).

56. Shah, R.; Devi, S. React. Funct. Polym., 31, p.1. (1996).

57. Shah, R. \& Devi, S. - Anal. Chim. Acta, 341, p.217 (1997).

58. Shah, R. \& Devi, S. - Talanta, 45, p.1089 (1998).

59. Salih, B.; Denizli, A.; Kavakli, C.; Say, R. \& Piskin, E. - Talanta, 46, p.1205 (1998).

60. Salih, B.; Say, R.; Denizli, A.; Genç, Ö. \& Piskin, E. Anal. Chim. Acta, 371, p.177 (1998).

61. Dujardin, M. C.; Cazé, C. \& Vroman, I. - React. Funct. Polym., 43, p.123, (2000).

62. Dabrowski, A.; Hubicki, Z.; Podko’scielny, P. \& Robens, E. - Chemosphere, 56, p.91 (2004).

63. Fréchet, J. M. J.; de Smet, M. D. \& Farrall, M. J - Polymer, 20, p.675 (1979).

64. Okawara, M.; Nakagawa, T. \& Inoto, E. - Kogyo Kagaku Zasshi, 60, p.73 (1957). 
65. Slovák, Z.; Smrz, M.; Docekal, B. \& Slováková, S. Anal. Chim. Acta, 111, p.243 (1979).

66. Lezzi, A.; Cobianco, S. \& Roggero, A. - J. Appl. Polym. Sci., 32, p.1877 (1994).

67. Maeda, H. \& Egawa, H. - Anal. Chim. Acta, 162, p.339 (1984).

68. Moyers, E. M. \& Fritz, J. S. - Anal. Chem., 48, p.1117 (1976).

69. Phillips, R. J. \& Fritz, J. S. - Anal. Chem., 50, p.1504 (1978).

70. Qu, R.; Sun, C.; Wang, C. Ji, C.; Sun, Y.; Guan, L.; Yu, M. \& Cheng, G. - Eur. Polym. J., 41, p.1525 (2005).

71. Qu, R.; Wang, C.; Ji, C.; Sun, C.; Sun, X. \& Cheng, G. - J. Appl. Polym. Sci., 95, p.1558 (2005).

72. Qu, R.; Wang, C.; Sun, C.; Ji, C. \& Cheng, G. - J. Appl. Polym. Sci., 92, p.1646 (2004).

73. Mondal, A. K. \& Das, A. K. - Anal. Chim. Acta, 477, p.73 (2003).

74. Guo, Y.; Din, B.; Liu, Y.; Chang, X.; Meng, S. \& Liu, J. - Talanta, 62, p.209 (2004).

75. Chattopadhyay, P.; Sinha, C. \& Pal, D. K. - Fresenius J. Anal. Chem., 357, p.368 (1997).

76. Das, D.; Das, A. K. \& Sinha, C. - Talanta, 48, p.1013 (1999).

77. Mondal, B. C.; Das, D. \& Das, A. K. - Anal. Chim. Acta, 450, p.223 (2001).

78. Berkel, P.M. V.; Driessen, W. L.; Reedijk, J.; Sherrington, D. C. \& Zitsmanis, A. - React. Funct. Polym., 27, p.15 (1995).

79. Baumann, T. F.; Reynolds, J. G. \& Fox, G. A. - React. Funct. Polym., 44, p.111 (2000).

80. Zuo, G. \& Muhammed, M. - React. Funct. Polym., 27, p.187 (1995).

81. Bicak, N.; Sherrington, D. C.; Sungur, S. \& Tan, N. - React. Funct. Polym., 54, p.141 (2003).
82. Bicak, N. \& Sherrington, D. C. - React. Funct. Polym., 27, p.155 (1995).

83. Thiagarajan, N. \& Subbaiyan, M. - J. Appl. Polym. Sci., 50, p.1195 (1993).

84. Biçak, N.; Sherrington, D. C. \& Senkal, B. F. - React. Funct. Polym., 41, p.69 (1999).

85. Sreedhar, M. K. \& Anirudhan, T. S. - J. Appl. Polym. Sci., 75, p.1261 (2000).

86. Sonmez, N. \& Bicak, N. - React. Funct. Polym., 51, p.55 (2002).

87. Sonmez, H. B.; Senkal, B.F.; Sherrington, D. C. \& Bicak, N. - React. Funct. Polym., 55, p.1 (2003).

88. Senkal, B.; Yavuz, E. \& Bicak, N. - Macromol. Symp., 217, p.169 (2004).

89. Sonmez, H. B. \& Bicak, N. - React. Funct. Polym., 61, p.33 (2004).

90. Yavuz, E.; Senkal, B. F. \& Bicak, N. - React. Funct. Polym., 65, p.121 (2005).

91. Rivas, B. L.; Pooley, S. A.; Aceitón, E. \& Geckeler, K. E. - J. Appl. Polym. Sci., 85, p.2559 (2002).

92. Keseci, K.; Say, R. \& Denizli, A. - E. Polym. J., 38, p.1443 (2002).

93. Rivas, B. L.; Ovando, P. \& Villegas, S. - J. Appl. Polym. Sci., 83, p.2595 (2002).

Enviado: 09/09/06

Reenviado: 14/02/07

Aprovado: 22/03/07 